\title{
Comparison of different definitions of the metabolic syndrome in relation to cardiovascular mortality in European men and women
}

\author{
The DECODE Study Group, Q. Qiao
}

Received: 1 June 2006 / Accepted: 31 July 2006 / Published online: 5 October 2006

(C) Springer-Verlag 2006

\begin{abstract}
Aims/hypothesis We estimated cardiovascular disease (CVD) mortality in individuals with the metabolic syndrome on the basis of different definitions.

Methods We collaboratively analysed data from 4,715 men and 5,554 women, who were aged 30 to 89 years, had a maximum follow-up of 7 to 16 years, and were drawn from nine European population-based cohorts. Cox regression analysis with age as time scale was performed to estimate hazard ratio (HR) for mortality, adjusting for cohort, serum total cholesterol and smoking.

Results The prevalence of the metabolic syndrome according to definitions of WHO, the National Cholesterol Education Program (NCEP), NCEP revised and the International Diabetes Federation (IDF) was 27.0\%, 25.9\%, 32.2\% and $35.9 \%$ respectively in men and $19.7 \%, 23.4 \%, 28.5 \%$ and $34.1 \%$ respectively in women. The corresponding HRs (95\% CIs) for CVD mortality were 2.09 (1.59-2.76), 1.74 (1.31-2.30), $1.72(1.31-2.26)$ and $1.51(1.15-1.99)$ in men, and $1.60(1.01-2.51), 1.39(0.89-2.18), 1.09(0.70-1.69)$ and $1.53(0.99-2.36)$ in women. The paired homogeneity test showed that in men the HR was higher with the WHO definition than with the IDF definition $(p=0.03)$. In women the HR was lower with the revised NCEP definitions than with either the WHO $(p=0.02)$ or the IDF $(p=0.01)$ definitions.
\end{abstract}

For details of members of the DECODE Study Group, see Electronic supplementary material.

Electronic supplementary material Supplementary material is available in the online version of this article at http://dx.doi.org/ $10.1007 / \mathrm{s} 00125-006-0438-6$ and is accessible to authorised users.

The DECODE Study Group, Q. Qiao $(\varangle)$

Department of Public Health, University of Helsinki,

PL41, Mannerheimintie 172,

FIN-00014 Helsinki, Finland

e-mail: qing.qiao@ktl.fi
With a few exceptions, HRs for full definitions of the syndrome were not significantly different from those for their single components.

Conclusions/interpretation Metabolic syndrome by the four definitions predicted CVD mortality in men, but the prediction was weak in women. Further research is required on the utility of definitions of the metabolic syndrome above and beyond that of its single components and in individual CVD risk stratification, particularly with regard to sex difference in the prediction.

Keywords Cardiovascular mortality · Definitions ·

Metabolic syndrome $\cdot$ Prevalence
Abbreviations
AACE American Association of Clinical Endocrinologists CVD cardiovascular disease
DECODE Diabetes Epidemiology: Collaborative Analysis Of Diagnostic Criteria in Europe
EGIR European Group for Study of Insulin Resistance
ESM electronic supplementary material
FPG fasting plasma glucose
2hPG plasma glucose $2 \mathrm{~h}$ after 75 -g glucose load
HR hazard ratio
IDF International Diabetes Federation
NCEP National Cholesterol Education Program
PAR population attributable risk

\section{Introduction}

Four major definitions of the metabolic syndrome have been proposed by different expert groups: WHO in 1998 [1] (revised 1999 [2]); the European Group for the Study of 
Insulin Resistance (EGIR) in 1999 [3]; the National Cholesterol Education Program Adult Treatment Expert Panel III (NCEP) in 2001 [4, 5] (revised in 2004 [6]); and the American Association of Clinical Endocrinologists (AACE) in 2003 [7, 8]. The WHO and the EGIR definitions have been proposed primarily for research purposes and the NCEP and AACE definitions for clinical use. The latter definition is less strict than others and intended as a guideline for physicians to define the metabolic syndrome. The major components of the metabolic syndrome included in these definitions are similar, but components and their diagnostic threshold values are emphasised differently in different definitions. In addition to the already existing definitions, a new definition, outlined by an International Diabetes Federation (IDF) consensus group, was issued in 2005 in an attempt to unify the existing definitions [9, 10]. This IDF definition emphasises the primary importance of central obesity, as assessed by waist circumference with ethnicity-specific cutoffs, and also considers it to be a prerequisite.

As summarised in a recent systematic review [11], several prospective studies have evaluated the association of either the WHO or the NCEP definition or both with the risk of cardiovascular disease (CVD). Although the results of different studies have not been uniform, meta-analyses have shown that the metabolic syndrome by the WHO definition was associated with a 1.9-fold increase and by the NCEP definition with a 1.7 -fold increase in CVD risk [11]. To our knowledge, the relationship of the IDF definition of the metabolic syndrome with CVD risk has so far been evaluated and compared with other definitions in only one prospective study [12].

In the present paper, based on data from nine European cohort studies participating in the Diabetes Epidemiology: Collaborative Analysis Of Diagnostic Criteria in Europe (DECODE), we determined the prevalence of the metabolic syndrome by the IDF definition as compared with that obtained by the WHO and the NCEP (original and revised) definitions and examined the relation of these different definitions of the syndrome with CVD, non-CVD and all-cause mortality.

\section{Subjects and methods}

Study populations

A total of 10,269 individuals (4,715 men and 5,554 women) from nine cohorts of seven studies formed the present study population. For 10,207 of these $(4,679$ men, 5,528 women) it was possible to make a correct classification with regard to cause-specific mortality. Individuals with previously diagnosed diabetes were not included in the data analysis, since one of the cohorts did not include individuals with previously diagnosed diabetes. All the studies (for details, see Electronic supplementary material [ESM]) were population-based and their baseline surveys were conducted around the early 1990s. The maximum follow-up time ranged from 6.6 to 16.0 years. The age range in the entire study population was from 30 to 89 years, with mean ages ranging from 46 to 62 years in different cohorts.

The recruitment of the DECODE cohorts has been described in detail previously [13-18]. Briefly, researchers who had conducted epidemiological studies in Europe on diabetes and impairment of glucose regulation, using a standard 2-h 75-g OGTT, were invited to participate. Individual data on fasting and 2-h glucose concentrations and a number of other variables were sent to the Diabetes and Genetic Epidemiology Unit of the National Public Health Institute in Helsinki, Finland, for collaborative data analyses. Detailed information on baseline participation rate and methods used in waist circumference and blood pressure measurements and laboratory assays is presented in ESM Table 1. Each study had Ethics Committee approval in accordance with local requirements, and the Ethics Committee of the National Public Health Institute has approved the current study on the metabolic syndrome and related issues based on the DECODE database. Informed consent was obtained from each individual.

Definition of the metabolic syndrome in the present study

Since data on urinary protein excretion and on dyslipidaemia treatment were not available, the definitions of the metabolic syndrome used in the present study were modified slightly.

Individuals with fasting plasma glucose (FPG) $\geq 6.1 \mathrm{mmol} / 1 \mathrm{and} /$ or 2 -h post-load plasma glucose $(2 \mathrm{hPG})$ $\geq 7.8 \mathrm{mmol} / \mathrm{l}$ and/or insulin resistance were considered to have the WHO metabolic syndrome [2], if, in addition, they had two or more of the following other components: (1) WHR $>0.90$ in men $(>0.85$ in women) and/or BMI $>30 \mathrm{~kg} / \mathrm{m}^{2}$; (2) blood pressure $\geq 140 / 90 \mathrm{mmHg}$ or use of antihypertensive drugs; (3) serum triacylglycerol $\geq 1.7 \mathrm{mmol} / \mathrm{l}$ and/or HDL-cholesterol $<0.9 \mathrm{mmol} / 1$ in men and $<1.0 \mathrm{mmol} / 1$ in women. Insulin resistance was defined by the top quartile of the fasting insulin concentration among non-diabetic individuals in the background population. Because the insulin measurements were not standardised between studies, the quartile cut-off points were calculated separately for each individual cohort, and separately for men and women.

The NCEP definition [4, 5] does not have any prerequisite; a diagnosis can be made if a person has three or more of the following five components: (1) waist circumference $>102 \mathrm{~cm}$ in men and $>88 \mathrm{~cm}$ in women; 
(2) FPG $\geq 6.1 \mathrm{mmol} / 1$; (3) blood pressure $\geq 130 / 85 \mathrm{mmHg}$ or use of antihypertensive drugs; (4) serum triacylglycerol $\geq 1.7 \mathrm{mmol} / \mathrm{l}$; (5) serum HDL-cholesterol $<1.03 \mathrm{mmol} / 1$ in men and $<1.29 \mathrm{mmol} / 1$ in women.

In the revised NCEP definition [6], the FPG cut-off value was lowered from $6.1 \mathrm{mmol} / 1$ to $5.6 \mathrm{mmol} / \mathrm{l}$, as recommended by a report of the National Heart, Lung, and Blood Institute/American Heart Association.

According to the IDF definition [9, 10], a person can be defined as having metabolic syndrome if he/she has central obesity (defined as waist circumference $\geq 94 \mathrm{~cm}$ for men and $\geq 80 \mathrm{~cm}$ for women in Europids), plus any two of the following components: (1) serum triacylglycerol $\geq 1.7 \mathrm{mmol} / 1$; (2) serum HDL-cholesterol $<1.03 \mathrm{mmol} / 1$ in men and $<1.29 \mathrm{mmol} / \mathrm{l}$ in women; (3) systolic blood pressure $\geq 130$ or diastolic blood pressure $\geq 85 \mathrm{mmHg}$, or treatment of previously diagnosed hypertension; 4) FPG $\geq 5.6 \mathrm{mmol} / 1$.

\section{Definition of fatal events}

Vital status and the date and cause of death for deceased individuals were recorded for each individual who had attended the baseline examination. Individuals who had emigrated, and for whom the vital status could not be confirmed, were treated as censored at the time of emigration. The follow-up was almost complete, from $98 \%$ to $100 \%$ (Table 1). The International Classification of Diseases, 8th, 9th and 10th Revisions, were used to code the causes of death. The codes used for CVD were 401-448 (I10-I79 for the Tenth Revision); the non-CVD deaths include all other causes of deaths. Participants who died, but for whom information on the cause of death was not available, were not included in the calculation of CVD or non-CVD mortality.

Statistical analysis

SPSS for Windows (version 13.0) was used to calculate means and proportions. Cox proportional hazard model analyses were performed using the R 2.2.1 Program (http://www.r-project.org/), adjusting for cohort, total cholesterol and smoking, and using age as time scale. Hazard ratios (HRs) $(95 \%$ CIs) for mortality in relation to the metabolic syndrome of different definitions and single risk factor components of these definitions were estimated. The assumption of the proportionality was tested using the 'Cox.zph (fit)' package incorporated in the R Program. A global $\chi^{2}$ test as well as the per-variable $\chi^{2}$ test was made, and there was no statistical evidence against the proportional hazard assumption for a Cox model fit ( $p$ values $>0.05$ for all tests). Meta-analysis using the method detailed by Fleiss [19] was performed based on individual data of each of the seven studies separately. The individual $\beta$-coefficients for each study as well as the combined overall $\beta$-coefficient of all studies are presented in Fig. 1a-f. A fixed rather than a random effects approach was chosen because the statistic $Q$ for measuring study-to-study

Table 1 Demographic and follow-up information on the cohort included

\begin{tabular}{|c|c|c|c|c|c|c|c|c|c|c|c|}
\hline \multirow[t]{3}{*}{ Cohorts } & \multirow{3}{*}{$\begin{array}{l}\text { Number } \\
\text { of } \\
\text { subjects }\end{array}$} & \multirow{3}{*}{$\begin{array}{l}\text { Age in years, } \\
\text { mean (range) }\end{array}$} & \multirow{3}{*}{$\begin{array}{l}\text { Men } \\
(\%)\end{array}$} & \multirow{3}{*}{$\begin{array}{l}\text { Completeness } \\
\text { of follow-up } \\
(\%)\end{array}$} & \multirow{3}{*}{$\begin{array}{l}\text { Maximum } \\
\text { duration of } \\
\text { follow-up } \\
\text { (years) }\end{array}$} & \multicolumn{6}{|c|}{ Number of deaths $(\%)$} \\
\hline & & & & & & \multicolumn{2}{|l|}{ CVD } & \multicolumn{2}{|l|}{ Non-CVD } & \multicolumn{2}{|l|}{ All-cause } \\
\hline & & & & & & Men & Women & Men & Women & Men & Women \\
\hline $\begin{array}{l}\text { Cremona, } \\
\text { Italy, }\end{array}$ & 1,909 & $58(40-88)$ & 43.7 & 100.0 & 6.9 & $26(3.1)$ & $18(1.7)$ & $51(6.1)$ & $26(2.4)$ & $81(9.7)$ & $47(4.4)$ \\
\hline $\begin{array}{l}\text { MONICA, } \\
\text { Finland, } 1992\end{array}$ & 1,847 & $54(44-64)$ & 45.5 & 100.0 & 12.0 & $36(4.3)$ & $10(1.0)$ & $57(6.8)$ & $41(4.1)$ & $93(11.1)$ & $51(5.1)$ \\
\hline $\begin{array}{l}\text { Hoorn, the } \\
\text { Netherlands }\end{array}$ & 2,379 & $62(49-77)$ & 46.1 & 97.3 & 10.2 & $67(6.2)$ & $32(2.5)$ & $94(8.7)$ & $79(6.2)$ & $177(16.1)$ & $118(9.2)$ \\
\hline $\begin{array}{l}\text { Newcastle, } \\
\text { UK }\end{array}$ & 735 & $55(30-76)$ & 51.0 & 100.0 & 10.6 & $25(6.7)$ & $8(2.2)$ & $33(8.8)$ & $24(6.7)$ & $59(15.7)$ & $32(8.9)$ \\
\hline $\begin{array}{l}\text { MONICA, } \\
\text { Poland }\end{array}$ & 351 & $58(44-73)$ & 47.3 & 98.6 & 6.6 & $13(7.9)$ & $2(1.1)$ & $4(2.4)$ & $3(1.7)$ & $18(10.8)$ & $9(4.9)$ \\
\hline $\begin{array}{l}\text { MONICA, } \\
\text { Sweden, } 1986\end{array}$ & 417 & $46(30-64)$ & 50.1 & 100.0 & 16.0 & $14(6.8)$ & $4(2.0)$ & $11(5.4)$ & $7(3.4)$ & $29(13.9)$ & $15(7.2)$ \\
\hline $\begin{array}{l}\text { MONICA, } \\
\text { Sweden, } 1992\end{array}$ & 696 & $47(30-64)$ & 47.1 & 100.0 & 12.0 & $4(1.2)$ & $1(0.3)$ & $9(2.8)$ & $8(2.2)$ & $16(4.9)$ & $12(3.3)$ \\
\hline $\begin{array}{l}\text { MONICA, } \\
\text { Sweden, } 1994\end{array}$ & 909 & $52(30-74)$ & 48.4 & 100.0 & 8.0 & $8(1.8)$ & $4(0.9)$ & $10(2.3)$ & $7(1.5)$ & $25(5.7)$ & $16(3.4)$ \\
\hline Ely, UK & 1,026 & $54(40-69)$ & 41.4 & 99.2 & 15.7 & $20(4.7)$ & $7(1.2)$ & $33(7.8)$ & $38(6.3)$ & $53(12.5)$ & $45(7.5)$ \\
\hline Total & 10,269 & $56(30-88)$ & 45.9 & - & 16.0 & $213(4.6)$ & 86 (1.6) & $302(6.5)$ & $233(4.2)$ & $551(11.7)$ & $345(6.2)$ \\
\hline
\end{tabular}



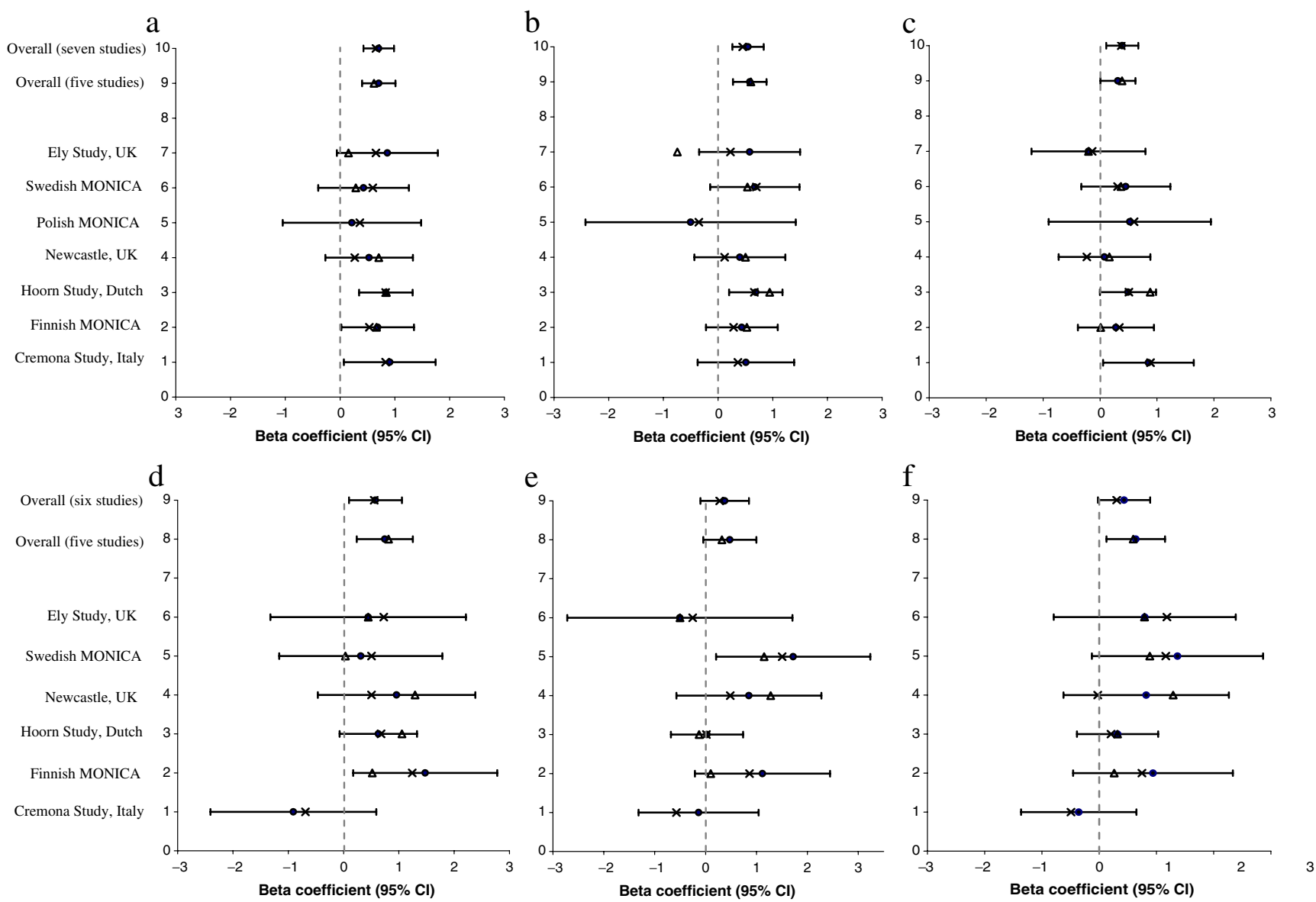

Fig. 1 Individual and overall beta coefficients for CVD mortality in men $(\mathbf{a}-\mathbf{c})$ and women $(\mathbf{d}-\mathbf{f})$ with the metabolic syndrome by $(\mathbf{a}, \mathbf{d})$ WHO, (b, e) NCEP and (c, f) IDF definitions, as compared with those without the syndrome using the same definition. Cox regression analysis using age as time scale and adjusted for cohort, cholesterol and smoking were used. - point estimates; error bars, 95\% CIs of point estimates in all individuals; $x$ point estimates in non-diabetic individuals; $\Delta$ point estimates in persons without prior history of CVD variation in effect size was not statistically different from zero (for the IDF metabolic syndrome $Q=3.5,6 d f$ for men and $Q=6.04,5 d f$ for women, all $p>0.10$ ) [19]. Since only two CVD deaths were observed for Polish women, neither of whom had the metabolic syndrome, it was not possible to perform the analysis for Polish women. They were not included in Fig. 1a-f, but were included in the pooled data analysis.

Except for the data presented in Fig. 1a-f, data from all other analyses shown in the present study were made based on pooled data adjusting for cohort in order to increase the statistical power. The overall HRs estimated using Fleiss's method based on the individual studies was approximately equal to those based on the pooled data analysis of all studies given the same study population.

Based on the pooled data, paired homogeneity tests were applied, using the 'Car' package in the R 2.2.1 program, to test the null hypothesis that the multivariate adjusted $\beta$ coefficients for CVD mortality in relation to the metabolic syndrome by different definitions were not statistically different from each other. The hypothesis is rejected if the $p$ value of the test is less than 0.05 , and the test then indicates that the predicted CVD mortality is different with different definitions. The same method was also applied to test the differences in effect sizes between a full definition and its single components.

The population attributable risk (PAR) and its 99\% CI were calculated using the censored bootstrap method described by Davidson and Hinkley [20]. We fitted the Cox proportional hazard model in each of the re-sampling iterations to obtain cohort-, cholesterol- and smokingadjusted estimates of the HR, and calculated the corresponding estimate of the exposure probability. The mean of the 10,000 bootstrap samples of the PAR and the $99.5 \%$ and $0.5 \%$ percentile points $(99 \% \mathrm{CI})$ are reported. The formula for calculating the PAR was: $\operatorname{PAR}=\operatorname{Pr}(E)(H R-1) /[\operatorname{Pr}(E)(H R-1)+1]$, where $\operatorname{Pr}$ (E) is the prevalence of each risk factor and HR denotes the HR of the factor estimated from a Cox model. 


\section{Results}

The number of individuals, their demographic characteristics, the completeness of follow-up and the number of deaths in each study cohort are shown in Table 1 . Table 2 shows the baseline risk factor characteristics and the prevalence of risk factor components of the metabolic syndrome, as well as the prevalence of the metabolic syndrome by different definitions in men and women in the pooled study population. The overall prevalence of the metabolic syndrome in men by the WHO, the NCEP original, the NCEP revised and the IDF definitions was $27.0 \%, 25.9 \%, 32.2 \%$ and $35.9 \%$. In women it was $19.7 \%$, $23.4 \%, 28.5 \%$ and $34.1 \%$, respectively. There was a considerable discrepancy between individuals identified by the different definitions. Of 2,116 men who had the metabolic syndrome by any of the three definitions of the WHO, NCEP and IDF, only 707 (33.4\%) met the criteria of all three. Among 2,096 women with the metabolic syndrome by any of the three definitions, $793(37.8 \%)$ had the syndrome by all three definitions. When this comparison was made by replacing the original NCEP definition with the revised NCEP definition, the concordance rates were $36.1 \%$ in men and $40.9 \%$ in women.

The associations of individual risk factors with CVD mortality were calculated per one standard deviation increase (decrease for HDL-cholesterol) in each risk factor to allow comparisons between factors. Among the factors studied, HDL-cholesterol, 2hPG, systolic blood pressure, and waist circumference followed by triacylglycerol in men, and in women systolic blood pressure, triacylglycerol, $2 \mathrm{hPG}$ and FPG were the most important risk factors for CVD mortality (Table 3). The effect sizes of dichotomous variables of the individual factors defined using different definitions of the metabolic syndrome were also estimated, and the HRs are shown in Table 4. The HR of smoking vs non-smoking with regard to CVD mortality was 2.11 (1.43$3.11)$ in men and $2.80(1.67-4.71)$ in women.

Table 2 Baseline characteristics of men and women in the combined study cohorts

\begin{tabular}{|c|c|c|c|}
\hline Characteristic & Men $(n=4,715)$ & Women $(n=5,554)$ & $p$ value \\
\hline FPG $(\mathrm{mmol} / \mathrm{l})$ & $5.53(1.00)$ & $5.31(1.00)$ & $<0.001$ \\
\hline 2hPG (mmol/l) & $5.56(1.00)$ & $5.82(1.00)$ & $<0.001$ \\
\hline Triacylglycerol $(\mathrm{mmol} / \mathrm{l})$ & $1.44(1.01)$ & $1.23(1.01)$ & $<0.001$ \\
\hline Total cholesterol (mmol/l) & $6.05(1.00)$ & $6.22(1.00)$ & $<0.001$ \\
\hline HDL (mmol/l) & $1.20(1.00)$ & $1.46(1.00)$ & $<0.001$ \\
\hline Systolic blood pressure $(\mathrm{mmHg})$ & $138(0.28)$ & $135(0.26)$ & $<0.001$ \\
\hline Diastolic blood pressure $(\mathrm{mmHg})$ & $83(0.17)$ & $80(0.15)$ & $<0.001$ \\
\hline $\operatorname{BMI}\left(\mathrm{kg} / \mathrm{m}^{2}\right)$ & $26.5(0.06)$ & $26.4(0.06)$ & 0.32 \\
\hline WHR & $0.94(0.00)$ & $0.82(0.00)$ & $<0.001$ \\
\hline Waist circumference $(\mathrm{cm})$ & $94.5(0.16)$ & $83.7(0.14)$ & $<0.001$ \\
\hline Current smoking, number (\%) & $1,400(29.7)$ & $1,136(20.5)$ & $<0.001$ \\
\hline \multicolumn{4}{|l|}{ Prevalence of components of different definitions of the metabolic syndrome, number (\%) } \\
\hline \multicolumn{4}{|l|}{ Glucose abnormality } \\
\hline WHO: $\mathrm{FPG} \geq 6.1 \mathrm{mmol} / 1$ and/or $2 \mathrm{hPG} \geq 7.8 \mathrm{mmol} / 1$ & $1,254(26.6)$ & $1,165(21.0)$ & $<0.001$ \\
\hline NCEP: $F P G \geq 6.1 \mathrm{mmol} / 1$ & $951(20.2)$ & $661(11.9)$ & $<0.001$ \\
\hline NCEP revised, IDF: FPG $\geq 5.6 \mathrm{mmol} / 1$ & $2,118(44.9)$ & $1,767(31.8)$ & $<0.001$ \\
\hline \multicolumn{4}{|l|}{ Dyslipidaemia } \\
\hline WHO: triacylglycerol $\geq 1.7 \mathrm{mmol} / 1$ and/or $\mathrm{HDL}<0.9 \mathrm{mmol} / 1$ in $\mathrm{men},<1.0 \mathrm{mmol} / 1$ in women & $1,860(39.4)$ & $1,432(25.8)$ & $<0.001$ \\
\hline NCEP, IDF: triacylglycerol $\geq 1.7 \mathrm{mmol} / 1$ & $1,717(36.4)$ & $1,322(23.8)$ & $<0.001$ \\
\hline NCEP, IDF: HDL $<1.03 \mathrm{mmol} / 1$ in $\mathrm{men},<1.29 \mathrm{mmol} / 1$ in women & $1,288(27.3)$ & $1,612(29.0)$ & 0.06 \\
\hline \multicolumn{4}{|l|}{ Elevated blood pressure $(\mathrm{mmHg})$} \\
\hline Blood pressure $\geq 140 / 90$ or on treatment & $2,414(51.2)$ & $2,612(47.0)$ & $<0.001$ \\
\hline Blood pressure $\geq 130 / 85$ or on treatment & $3,257(69.1)$ & $3,501(63.0)$ & $<0.001$ \\
\hline \multicolumn{4}{|l|}{ Central obesity } \\
\hline WHO: $\mathrm{BMI}>30 \mathrm{~kg} / \mathrm{m}^{2}$ or WHR $>0.90$ in men, $>0.85$ in women & $2,881(61.1)$ & $1,832(33.0)$ & $<0.001$ \\
\hline NCEP: waist $>102 \mathrm{~cm}$ in men, $>88 \mathrm{~cm}$ in women & $919(19.5)$ & $1,738(31.3)$ & $<0.001$ \\
\hline IDF: waist $\geq 94 \mathrm{~cm}$ in $\mathrm{men}, \geq 80 \mathrm{~cm}$ in women & $2,376(50.4)$ & $3,304(59.5)$ & $<0.001$ \\
\hline \multicolumn{4}{|l|}{ Prevalence of metabolic syndrome, number (\%) } \\
\hline WHO & $1,271(27.0)$ & $1,092(19.7)$ & $<0.001$ \\
\hline NCEP & $1,219(25.9)$ & $1,301(23.4)$ & $<0.001$ \\
\hline NCEP revised & $1,520(32.2)$ & $1,585(28.5)$ & $<0.001$ \\
\hline IDF & $1,692(35.9)$ & $1,892(34.1)$ & 0.05 \\
\hline
\end{tabular}

Values are age- and cohort-adjusted mean (SE), or number (\%) 
Table 3 HRs $(95 \%$ CI) for CVD mortality corresponding to a one standard deviation increase in risk factors in all subjects including newly diagnosed diabetes

\begin{tabular}{lll}
\hline $\begin{array}{l}\text { Variable (one SD } \\
\text { for men/women) }\end{array}$ & Men & Women \\
\hline $\begin{array}{l}\text { Waist }(10.0 / 11.7 \mathrm{~cm}) \\
\text { BMI }\left(3.5 / 4.6 \mathrm{~kg} / \mathrm{m}^{2}\right)^{\mathrm{a}}\end{array}$ & $1.21(1.06-1.39)$ & $1.14(0.91-1.41)$ \\
$\begin{array}{l}\text { Systolic blood pressure } \\
(20 / 22 \mathrm{mmHg})\end{array}$ & $1.27(1.12-1.45)$ & $1.35(1.10-1.66)$ \\
$\begin{array}{l}\text { Diastolic blood pressure } \\
(11 / 11 \mathrm{mmHg})\end{array}$ & $1.13(0.99-1.30)$ & $1.19(0.97-1.47)$ \\
Total cholesterol & $1.15(1.00-1.32)$ & $1.01(0.81-1.28)$ \\
$(1.12 / 1.26 \mathrm{mmol} / \mathrm{l})$ & & \\
$\begin{array}{l}\text { Triacylglycerol } \\
(1.08 / 0.74 \mathrm{mmol} / \mathrm{l})\end{array}$ & $1.20(1.08-1.34)$ & $1.24(1.05-1.47)$ \\
$\mathrm{HDL}(0.34 / 0.36 \mathrm{mmol} / \mathrm{l})$ & $0.68(0.58-0.79)$ & $0.85(0.67-1.06)$ \\
FPG $(0.98 / 0.84 \mathrm{mmol} / \mathrm{l})$ & $1.16(1.08-1.25)$ & $1.16(1.02-1.33)$ \\
$2 \mathrm{hPG}(2.51 / 2.31 \mathrm{mmol} / \mathrm{l})^{\mathrm{a}}$ & $1.28(1.18-1.39)$ & $1.17(1.01-1.34)$ \\
\hline
\end{tabular}

The time scale is age for all models, adjusted for total cholesterol, smoking and cohort

${ }^{\mathrm{a}}$ With missing values

In men the presence of the metabolic syndrome by the WHO, NCEP, NCEP revised and IDF definitions increased CVD mortality significantly, but in women only the WHO metabolic syndrome remained significant after multivariate adjustment (Table 4), with borderline significance for the other definitions. The paired homogeneity test showed that there was no difference in the prediction of CVD mortality between the WHO and the NCEP definitions $(p=0.16$ in men and $p=0.42$ in women), between the NCEP and the IDF definitions ( $p=0.51$ in men and $p=0.49$ in women), and between the WHO and the IDF definitions in women $(p=0.94)$. The prediction of CVD mortality was, however, stronger in men diagnosed by the WHO definition than in those diagnosed by the IDF definition $(p=0.03)$. When the NCEP definition was replaced with the NCEP revised definition, the test results did not change in men, but in women the NCEP revised definition related to a significantly lower CVD risk than the WHO definition $(p=0.02)$ and the IDF definition $(p=0.01)$.

The paired homogeneity test showed that the effect sizes of a full definition of the metabolic syndrome were not statistically significantly different from their individual components $(p>0.05)$ with only a few exceptions. Thus a lower HR for dyslipidaemia $(p=0.015)$ and for IFG/IGT $(p=0.021)$ defined by the WHO criteria in men, and a higher HR for elevated blood pressure $(p=0.046)$ and triacylglycerol $(p=0.022)$ defined by the revised NCEP criteria in women were observed, as compared respectively with the corresponding full definitions.

The respective PAR for the WHO, NCEP, NCEP revised and IDF definitions of the metabolic syndrome with regard to CVD mortality was $0.21(0.09-0.34), 0.16(0.04-0.28)$, $0.19(0.06-0.32)$ and $0.15(0.01-0.29)$ in men, and 0.11 $(-0.03-0.28), 0.10(-0.06-0.28), 0.04(-0.13-0.23)$ and $0.18(-0.04-0.41)$ in women. The PAR for raised blood pressure, high triacylglycerol and low HDL by the NCEP/ IDF definition was $0.47(0.22-0.69), 0.11(-0.04-0.26)$ and $0.16(0.05-0.29)$ in men, and $0.51(0.10-0.87), 0.17$ $(0.001-0.36)$ and $0.08(-0.10-0.29)$ in women.

To check the extent to which the results obtained might be modified by a prior history of CVD or by previously undiagnosed diabetic status, the same analyses were also run after excluding individuals with prior CVD at baseline survey (five of the studies used have this information), as well as after excluding persons with newly diagnosed diabetes from the analyses. The point estimates of these analyses were plotted side by side with the estimates based on all individuals (Fig. 1a-f). The overall $\beta$ coefficients decreased for most of the definitions, but remained unchanged for the IDF definition (Fig. 1c) in men and for the WHO definition in women (Fig. 1d) after newly diagnosed diabetic individuals were excluded from the data analyses (Fig. 1a-f). However, the overall $\beta$ coefficients in persons who were free of CVD at baseline examination changed in different directions, increasing slightly for the IDF definition in men (Fig. 1c) and for the WHO definition in women (Fig. 1d), while remaining unchanged for the NCEP definition in men (Fig. 1b), and decreasing for the WHO definition in men (Fig. 1a) and for the NCEP (Fig. 1e) and the IDF (Fig. 1f) definitions in women. The overall HR for CVD mortality in relation to the metabolic syndrome was not markedly driven by either the prior CVD history or the undiagnosed diabetic status.

The metabolic syndrome was not related significantly to non-cardiovascular mortality by any of the four definitions in men or women (Table 5). By all four definitions, metabolic syndrome was significantly related to all-cause mortality in men, whereas in women no such significant relationships were observed.

\section{Discussion}

More than one-third of the DECODE study population met the IDF definition for the metabolic syndrome, which is higher than the proportion given by either the WHO or the original NCEP definition, but rather close to that obtained with the revised NCEP definition in men. Despite the differences in the definitions and in the resulting prevalences, all definitions of the metabolic syndrome were associated with increased CVD mortality in men, but the association was weak in women. The effect sizes for many single components were as high as those for the full definitions of the syndrome. 
Table 4 HRs showing the relationship of different definitions of the metabolic syndrome and their individual components with CVD death, compared with those without the metabolic syndrome or without each risk factor component of these definitions in all subjects including newly diagnosed diabetes

\begin{tabular}{|c|c|c|c|c|c|}
\hline & \multirow{2}{*}{$\begin{array}{l}\text { CVD } \\
\text { death, } n\end{array}$} & \multicolumn{4}{|l|}{$\operatorname{HR}(95 \% \mathrm{CI})^{\mathrm{a}}$} \\
\hline & & Crude & $\begin{array}{l}\text { Model } 1 \\
\text { Age-adjusted }\end{array}$ & $\begin{array}{l}\text { Model } 2 \\
\text { Age+cohort }\end{array}$ & $\begin{array}{l}\text { Model } 3 \\
\text { Multivariate }\end{array}$ \\
\hline \multicolumn{6}{|l|}{ Men } \\
\hline WHO metabolic syndrome & 99 & $2.49(1.88-3.28)$ & $1.92(1.47-2.52)$ & $2.05(1.56-2.70)$ & $2.09(1.59-2.76)$ \\
\hline NCEP metabolic syndrome & 84 & $1.94(1.46-2.57)$ & $1.67(1.27-2.21)$ & $1.76(1.33-2.33)$ & $1.74(1.31-2.30)$ \\
\hline NCEP revised & 102 & $2.00(1.52-2.64)$ & $1.68(1.28-2.19)$ & $1.76(1.34-2.31)$ & $1.72(1.31-2.26)$ \\
\hline IDF metabolic syndrome & 105 & $1.79(1.36-2.36)$ & $1.44(1.10-1.89)$ & $1.51(1.15-1.99)$ & $1.51(1.15-1.99)$ \\
\hline $\mathrm{FPG} \geq 6.1$ and/or $2 \mathrm{hPG} \geq 7.8 \mathrm{mmol} / 1$ & 89 & $2.07(1.56-2.74)$ & $1.55(1.18-2.03)$ & $1.56(1.18-2.07)$ & $1.56(1.18-2.07)$ \\
\hline $\mathrm{FPG} \geq 6.1 \mathrm{mmol} / 1$ & 66 & $1.84(1.37-2.49)$ & $1.48(1.10-1.98)$ & $1.54(1.14-2.08)$ & $1.53(1.13-2.07)$ \\
\hline $\mathrm{FPG} \geq 5.6 \mathrm{mmol} / 1$ & 120 & $1.62(1.23-2.14)$ & $1.28(0.98-1.68)$ & $1.35(1.01-1.79)$ & $1.33(1.00-1.77)$ \\
\hline $\begin{array}{l}\text { Triacylglycerol } \geq 1.7 \text { and/or } \\
\text { HDL-C }<0.9 \mathrm{mmol} / 1\end{array}$ & 101 & $1.41(1.07-1.86)$ & $1.44(1.10-1.88)$ & $1.52(1.16-2.00)$ & $1.43(1.08-1.88)$ \\
\hline Triacylglycerol $\geq 1.7 \mathrm{mmol} / 1$ & 91 & $1.33(1.00-1.75)$ & $1.40(1.06-1.83)$ & $1.48(1.12-1.95)$ & $1.37(1.03-1.82)$ \\
\hline $\mathrm{HDL}<1.03 \mathrm{mmol} / 1$ & 82 & $1.71(1.29-2.28)$ & $1.59(1.21-2.10)$ & $1.66(1.25-2.20)$ & $1.68(1.27-2.23)$ \\
\hline $\begin{array}{l}\text { Blood pressure } \geq 140 / 90 \mathrm{mmHg} \\
\text { or treated }\end{array}$ & 153 & $2.54(1.87-3.44)$ & $1.82(1.35-2.46)$ & $1.91(1.40-2.60)$ & $2.04(1.50-2.79)$ \\
\hline $\begin{array}{l}\text { Blood pressure } \geq 130 / 85 \mathrm{mmHg} \\
\text { or treated }\end{array}$ & 184 & $2.96(1.99-4.40)$ & $2.10(1.42-3.12)$ & $2.19(1.47-3.27)$ & $2.30(1.54-3.43)$ \\
\hline BMI $>30 \mathrm{~kg} / \mathrm{m}^{2}$ or $\mathrm{WHR}>0.90$ & 161 & $2.03(1.48-2.80)$ & $1.56(1.14-2.14)$ & $1.68(1.17-2.40)$ & $1.64(1.14-2.34)$ \\
\hline Waist $>102 \mathrm{~cm}$ & 63 & $1.79(1.32-2.42)$ & $1.53(1.14-2.06)$ & $1.52(1.13-2.04)$ & $1.56(1.16-2.11)$ \\
\hline Waist $\geq 94 \mathrm{~cm}$ & 136 & $1.79(1.34-2.38)$ & $1.42(1.07-1.88)$ & $1.44(1.08-1.91)$ & $1.48(1.11-1.97)$ \\
\hline \multicolumn{6}{|l|}{ Women } \\
\hline WHO metabolic syndrome & 33 & $2.61(1.68-4.05)$ & $1.54(0.99-2.40)$ & $1.56(0.99-2.45)$ & $1.60(1.01-2.51)$ \\
\hline NCEP metabolic syndrome & 34 & $2.17(1.40-3.37)$ & $1.47(0.95-2.29)$ & $1.47(0.94-2.29)$ & $1.39(0.89-2.18)$ \\
\hline NCEP revised & 36 & $1.83(1.19-2.82)$ & $1.14(0.73-1.76)$ & $1.12(0.72-1.73)$ & $1.09(0.70-1.69)$ \\
\hline IDF metabolic syndrome & 47 & $2.38(1.55-3.65)$ & $1.52(0.98-2.33)$ & $1.50(0.97-2.32)$ & $1.53(0.99-2.36)$ \\
\hline $\mathrm{FPG} \geq 6.1 \mathrm{and} /$ or $2 \mathrm{hPG} \geq 7.8 \mathrm{mmol} / 1$ & 37 & $2.93(1.90-4.51)$ & $1.55(1.00-2.40)$ & $1.61(1.03-2.50)$ & $1.69(1.08-2.63)$ \\
\hline $\mathrm{FPG} \geq 6.1 \mathrm{mmol} / 1$ & 26 & $3.31(2.07-5.28)$ & $2.13(1.33-3.41)$ & $2.24(1.37-3.64)$ & $2.17(1.33-3.55)$ \\
\hline $\mathrm{FPG} \geq 5.6 \mathrm{mmol} / 1$ & 35 & $1.49(0.96-2.29)$ & $1.07(0.70-1.66)$ & $1.06(0.67-1.68)$ & $1.08(0.69-1.72)$ \\
\hline $\begin{array}{l}\text { Triacylglycerol } \geq 1.7 \text { and/or } \\
\text { HDL-cholesterol }<1.0 \mathrm{mmol} / 1\end{array}$ & 38 & $2.32(1.51-3.56)$ & $1.82(1.18-2.81)$ & $1.85(1.20-2.85)$ & $1.77(1.13-2.77)$ \\
\hline Triacylglycerol $\geq 1.7 \mathrm{mmol} / 1$ & 36 & $2.35(1.52-3.62)$ & $1.81(1.17-2.79)$ & $1.83(1.18-2.84)$ & $1.81(1.14-2.86)$ \\
\hline $\mathrm{HDL}<1.29 \mathrm{mmol} / \mathrm{l}$ & 33 & $1.53(0.99-2.38)$ & $1.34(0.86-2.07)$ & $1.36(0.87-2.11)$ & $1.24(0.79-1.93)$ \\
\hline $\begin{array}{l}\text { Blood pressure } \geq 140 / 90 \mathrm{mmHg} \\
\text { or treated }\end{array}$ & 66 & $3.81(2.30-6.30)$ & $1.91(1.13-3.20)$ & $1.93(1.14-3.27)$ & $2.07(1.22-3.52)$ \\
\hline $\begin{array}{l}\text { Blood pressure } \geq 130 / 85 \mathrm{mmHg} \\
\text { or treated }\end{array}$ & 76 & $4.56(2.35-8.84)$ & $2.17(1.09-4.30)$ & $2.14(1.07-4.28)$ & $2.31(1.15-4.62)$ \\
\hline $\mathrm{BMI}>30 \mathrm{~kg} / \mathrm{m}^{2}$ or $\mathrm{WHR}>0.85$ & 39 & $1.71(1.12-2.63)$ & $1.33(0.86-2.04)$ & $1.23(0.78-1.95)$ & $1.21(0.77-1.92)$ \\
\hline Waist $>88 \mathrm{~cm}$ & 38 & $1.76(1.15-2.71)$ & $1.24(0.80-1.90)$ & $1.21(0.78-1.88)$ & $1.26(0.81-1.95)$ \\
\hline Waist $\geq 80 \mathrm{~cm}$ & 63 & $1.89(1.17-3.06)$ & $1.19(0.73-1.93)$ & $1.15(0.70-1.89)$ & $1.20(0.73-1.99)$ \\
\hline
\end{tabular}

${ }^{\text {a }}$ Crude HR calculated as mortality in subjects exposed/mortality in those not exposed. For Models $1-3$, age is the time scale. In Model 3 additional adjustments were made for cohort, smoking and total cholesterol.

An important strength of the DECODE study is that its database contains information on a large number of European men and women with almost complete followup with regard to cause-specific mortality. However, despite the large size of the study, the number of CVD deaths was still low in women.

The limitation of this collaborative data analysis was that the protocols and methods used to assess risk factors at baseline were not uniform in all seven studies, because studies included in the DECODE study had originally been conducted independently. However, as shown in ESM Table 1, the methods used for measurement of waist circumference and blood pressure and the laboratory assays for glucose and lipids were similar, although not standardised across studies. This may to a certain extent reduce the discrepancy in survey methods between studies. In addition, the cohort was included as a covariate in all data analyses where the data from different cohorts were pooled 
Table 5 HRs (95\% CI) showing the relationship of different definitions of the metabolic syndrome and their individual components with non-cardiovascular death (non-CVD) and death from all-causes, as compared with those without the metabolic syndrome or without each risk factor component of these definitions in all subjects including newly diagnosed diabetes

\begin{tabular}{|c|c|c|c|c|}
\hline & \multicolumn{2}{|l|}{ Non-CVD } & \multicolumn{2}{|l|}{ All causes } \\
\hline & Deaths, $n$ & HR & Deaths, $n$ & HR \\
\hline \multicolumn{5}{|l|}{ Men } \\
\hline WHO metabolic syndrome & 106 & $1.25(0.98-1.60)$ & 221 & $1.57(1.32-1.87)$ \\
\hline NCEP metabolic syndrome & 92 & $1.11(0.86-1.42)$ & 187 & $1.33(1.11-1.59)$ \\
\hline NCEP revised & 109 & $1.02(0.80-1.30)$ & 225 & $1.27(1.06-1.51)$ \\
\hline IDF metabolic syndrome & 129 & $1.10(0.87-1.39)$ & 251 & $1.26(1.06-1.49)$ \\
\hline $\mathrm{FPG} \geq 6.1$ and/or $2 \mathrm{hPG} \geq 7.8 \mathrm{mmol} / 1$ & 109 & $1.27(0.99-1.62)$ & 212 & $1.41(1.18-1.69)$ \\
\hline $\mathrm{FPG} \geq 6.1 \mathrm{mmol} / 1$ & 84 & $1.31(1.01-1.70)$ & 160 & $1.41(1.17-1.71)$ \\
\hline $\mathrm{FPG} \geq 5.6 \mathrm{mmol} / 1$ & 155 & $1.09(0.86-1.39)$ & 295 & $1.22(1.02-1.45)$ \\
\hline Triacylglycerol $\geq 1.7$ and/or HDL $<0.9 \mathrm{mmol} / 1$ & 120 & $0.97(0.76-1.23)$ & 240 & $1.17(0.98-1.39)$ \\
\hline Triacylglycerol $\geq 1.7 \mathrm{mmol} / 1$ & 109 & $0.96(0.75-1.23)$ & 218 & $1.15(0.96-1.38)$ \\
\hline $\mathrm{HDL}<1.03 \mathrm{mmol} / 1$ & 87 & $1.04(0.81-1.33)$ & 180 & $1.25(1.04-1.49)$ \\
\hline Blood pressure $\geq 140 / 90 \mathrm{mmHg}$ or treated & 197 & $1.42(1.11-1.82)$ & 373 & $1.60(1.33-1.93)$ \\
\hline Blood pressure $\geq 130 / 85 \mathrm{mmHg}$ or treated & 240 & $1.31(0.98-1.75)$ & 462 & $1.57(1.25-1.96)$ \\
\hline $\mathrm{BMI}>30 \mathrm{~kg} / \mathrm{m}^{2}$ or $\mathrm{WHR}>0.90$ & 216 & $1.50(1.12-2.01)$ & 402 & $1.50(1.21-1.87)$ \\
\hline Waist $>102 \mathrm{~cm}$ & 79 & $1.30(1.00-1.69)$ & 148 & $1.37(1.13-1.65)$ \\
\hline Waist $\geq 94 \mathrm{~cm}$ & 172 & $1.08(0.86-1.36)$ & 329 & $1.22(1.03-1.45)$ \\
\hline \multicolumn{5}{|l|}{ Women } \\
\hline WHO metabolic syndrome & 64 & $1.05(0.78-1.41)$ & 108 & $1.17(0.92-1.48)$ \\
\hline NCEP metabolic syndrome & 71 & $1.07(0.80-1.43)$ & 114 & $1.14(0.91-1.44)$ \\
\hline NCEP revised & 88 & $1.09(0.83-1.44)$ & 136 & $1.10(0.88-1.38)$ \\
\hline IDF metabolic syndrome & 99 & $1.07(0.82-1.40)$ & 160 & $1.20(0.97-1.49)$ \\
\hline $\mathrm{FPG} \geq 6.1 \mathrm{and} /$ or $2 \mathrm{hPG} \geq 7.8 \mathrm{mmol} / 1$ & 84 & $1.41(1.07-1.86)$ & 133 & $1.50(1.19-1.88)$ \\
\hline $\mathrm{FPG} \geq 6.1 \mathrm{mmol} / 1$ & 46 & $1.17(0.84-1.62)$ & 77 & $1.40(1.07-1.82)$ \\
\hline $\mathrm{FPG} \geq 5.6 \mathrm{mmol} / 1$ & 105 & $1.21(0.92-1.59)$ & 153 & $1.24(0.99-1.55)$ \\
\hline Triacylglycerol $\geq 1.7$ and/or HDL $<1.0 \mathrm{mmol} / 1$ & 70 & $0.99(0.74-1.33)$ & 117 & $1.16(0.92-1.47)$ \\
\hline Triacylglycerol $\geq 1.7 \mathrm{mmol} / 1$ & 68 & $1.03(0.77-1.40)$ & 112 & $1.19(0.93-1.51)$ \\
\hline $\mathrm{HDL}<1.29 \mathrm{mmol} / 1$ & 71 & $1.02(0.76-1.35)$ & 112 & $1.06(0.85-1.34)$ \\
\hline Blood pressure $\geq 140 / 90 \mathrm{mmHg}$ or treated & 133 & $1.03(0.78-1.36)$ & 218 & $1.24(0.98-1.56)$ \\
\hline Blood pressure $\geq 130 / 85 \mathrm{mmHg}$ or treated & 164 & $0.91(0.67-1.23)$ & 264 & $1.14(0.88-1.49)$ \\
\hline BMI $>30 \mathrm{~kg} / \mathrm{m}^{2}$ or WHR $>0.85$ & 103 & $1.34(1.02-1.77)$ & 160 & $1.33(1.06-1.67)$ \\
\hline Waist $>88 \mathrm{~cm}$ & 92 & $1.27(0.97-1.67)$ & 144 & $1.26(1.01-1.58)$ \\
\hline Waist $\geq 80 \mathrm{~cm}$ & 152 & $1.07(0.81-1.43)$ & 236 & $1.12(0.88-1.42)$ \\
\hline
\end{tabular}

The time scale is age for all models and adjustment for cohort, total cholesterol and smoking

together, and the results were similar to those based on the meta-analysis of individual studies.

Most of the population-based studies applying the WHO definition of the metabolic syndrome [12, 21-29] have modified it in a similar way to our study, using the top quartile of fasting plasma insulin as a proxy of insulin resistance and omitting microalbuminuria from the definition. The original NCEP definition or its slight modification has been applied in many studies [12, 22, 24-26, 28, 3037]. In a recent systematic review and meta-analysis [11], combining data for men and women, the overall estimate of the relative risk of CVD was 1.9 for studies that used the most exact WHO definition, and 1.7 for studies that used the original NCEP definition; the PAR varied from $12 \%$ to $17 \%$. The results of our study were close to these estimates. The only study so far comparing the prediction of CVD by the IDF, the WHO and the original NCEP definitions is the British Regional Heart Study of female participants [12], in which the age-adjusted HRs for CHD (fatal and non-fatal) were $1.3,1.5$ and 1.4 , respectively. Our corresponding point estimates of the age-adjusted HRs for CVD mortality in women were quite similar to those reported for British women.

In accordance with our study, several other studies have shown that individual components predicted the CVD risk by a similar magnitude to that predicted by the actual syndrome $[12,22,23,38]$. A study using the hyperinsulinaemic-euglycaemic clamp technique showed that about one third of the subjects who did not meet the NCEP criteria for the metabolic syndrome were insulin-resistant [39]. Importantly, these subjects were not significantly different from those meeting the NCEP criteria in regard to 
the prevalence of IFG and IGT, the glucose disposal rate, and all of the lipoprotein subclass changes, including increased large VLDL concentration and VLDL size, and decreased large HDL particles and HDL size, all of which would increase CVD risk [39]. Definitions of the metabolic syndrome are intended to promote intensive lifestyle modification and health care in people who are at increased risk of diabetes and CVD. Because the definitions require the presence of a certain number of dichotomously defined risk factors, all the definitions will miss individuals who have fewer factors but are at increased mortality risk. For these individuals, the definition of the metabolic syndrome does not offer any benefit with regard to the identification of problems and possible medical intervention. In this study, for example, the CVD mortality among newly diagnosed diabetic women with and without the WHO metabolic syndrome was $5.7 \%$ and $6.5 \%$, respectively. Thus diagnosis of the metabolic syndrome would give little additional prognostic value in the assessment of CVD risk in newly diagnosed diabetic women.

In conclusion, the findings of our population-based study raised questions about the utility of definitions of the metabolic syndrome in predicting CVD mortality. Further research is needed on the predictive value of the metabolic syndrome over and above that of its individual components and conventional multivariate CVD risk assessment scores, as well as on the differences in effect size between sexes.

Acknowledgements This analysis was carried out with the help of grants from Paulo Foundation, Finland, from Future Forum Research Grant 2004, from Novo Nordisk Foundation 2005, and from Finnish Academy (118492). The DECODE Study has been financially supported by unrestricted grants from Novo Nordisk, Bagsvaerd, Denmark, Novartis Pharma, Basel, Switzerland and AstraZeneca, Mölndal, Sweden.

Duality of interest The authors have stated that there was no duality of interest.

\section{Appendix}

In this DECODE study, the following were responsible for data analysis:

Q. Qiao, J. Pitkäniemi, W. G. Gao

Department of Public Health, University of Helsinki, Helsinki, Finland

Q. Qiao, W. G. Gao

Diabetes and Genetic Epidemiology Unit, Department of Health Promotion and Chronic Disease Prevention, National Public Health Institute, Helsinki, Finland

The writing committee for this DECODE study was:

Q. Qiao, J. Pitkäniemi, J. Tuomilehto, W. G. Gao,

Department of Public Health, University of Helsinki, Helsinki, Finland.
Q. Qiao, J. Tuomilehto, W. G. Gao

Diabetes and Genetic Epidemiology Unit, Department of Health Promotion and Chronic Disease Prevention, National Public Health Institute, Helsinki, Finland.

J. Tuomilehto

South Ostrobothnia Central Hospital, Seinäjoki, Finland.

K. Pyörälä

Department of Medicine, University of Kuopio, Kuopio, Finland.

B. Balkau

INSERM U258-IFR69, Paris, France.

K. Borch-Johnsen

Steno Diabetes Center, Gentofte, Denmark.

K. G. M. M. Alberti

Department of Medicine and Epidemiology and Public Health, University of Newcastle, Newcastle, UK and Department of Endocrinology, Imperial College, London, UK

\section{References}

1. Alberti KG, Zimmet PZ (1998) Definition, diagnosis and classification of diabetes mellitus and its complications. Part 1: diagnosis and classification of diabetes mellitus provisional report of a WHO consultation. Diabet Med 15:539-553

2. World Health Organization Consultation (1999) Definition, diagnosis and classification of diabetes mellitus and its complications. Part 1: diagnosis and classification of diabetes mellitus. Report No. 99.2. WHO, Geneva

3. Balkau B, Charles MA (1999) Comment on the provisional report from the WHO consultation. European Group for the Study of Insulin Resistance (EGIR). Diabet Med 16:442-443

4. Adult Treatment Panel III (2002) Third report of the National Cholesterol Education Program (NCEP) expert panel on detection, evaluation, and treatment of high blood cholesterol in adults (Adult Treatment Panel III) final report. Circulation 106:3143-3421

5. Expert Panel on Detection, Evaluation, and Treatment of High Blood Cholesterol in Adults (2001) Executive summary of the third report of the National Cholesterol Education Program (NCEP) expert panel on detection, evaluation, and treatment of high blood cholesterol in adults (Adult Treatment Panel III). JAMA 285:2486-2497

6. Grundy SM, Brewer HB Jr, Cleeman JI, Smith SC Jr, Lenfant C (2004) Definition of metabolic syndrome: report of the National Heart, Lung, and Blood Institute/American Heart Association conference on scientific issues related to definition. Arterioscler Thromb Vasc Biol 24:e13-e18

7. Bloomgarden ZT (2003) American Association of Clinical Endocrinologists (AACE) Consensus Conference on the Insulin Resistance Syndrome: 25-26 August 2002, Washington, DC. Diabetes Care 26:933-939

8. American College of Endocrinology Task Force on the Insulin Resistance Syndrome (2003) American College of Endocrinology position statement on the insulin resistance syndrome. Endocr Pract 9:237-252

9. Alberti KG, Zimmet P, Shaw J (2005) The metabolic syndromea new worldwide definition. Lancet 366:1059-1062

10. Alberti KGMM, Zimmet P, Shaw J (2006) Metabolic syndromea new world-wide definition. A consensus statement from the International Diabetes Federation. Diabet Med 23:469-480 
11. Ford ES (2005) Risks for all-cause mortality, cardiovascular disease, and diabetes associated with the metabolic syndrome: a summary of the evidence. Diabetes Care 28:1769-1778

12. Lawlor DA, Smith GD, Ebrahim S (2006) Does the new International Diabetes Federation definition of the metabolic syndrome predict CHD any more strongly than older definitions? Findings from the British Women's Heart and Health Study. Diabetologia 49:41-48

13. The DECODE Study Group (1999) Glucose tolerance and mortality: comparison of WHO and American Diabetes Association diagnostic criteria. Lancet 354:617-621

14. The DECODE Study Group (1998) Will new diagnostic criteria for diabetes mellitus change phenotype of patients with diabetes? Reanalysis of European epidemiological data. DECODE Study Group on behalf of the European Diabetes Epidemiology Study Group. Br Med J 317:371-375

15. The DECODE Study Group (2003) Is the current definition for diabetes relevant to mortality risk from all-cause, cardiovascular and non-cardiovascular disease? Diabetes Care 26:688-696

16. The DECODE Study Group (2001) Glucose tolerance and cardiovascular mortality: comparison of fasting and 2-hour diagnostic criteria. Arch Intern Med 161:397-405

17. The DECODE Study Group (2004) Prevalence of the metabolic syndrome and its relation to all-cause and cardiovascular mortality in nondiabetic European men and women. Arch Intern Med 164:1066-1076

18. The DECODE Study Group (2004) Plasma insulin and cardiovascular mortality in non-diabetic European men and women: a metaanalysis of data from eleven prospective studies. Diabetologia 47:1245-1256

19. Fleiss JL (1993) The statistical basis of meta-analysis. Stat Methods Med Res 2:121-145

20. Davidson AC, Hinkley DV (1997) Bootstrap methods and their application. Cambridge University Press, Cambridge

21. Bonora E, Kiechl S, Willeit J et al (2003) Carotid atherosclerosis and coronary heart disease in the metabolic syndrome: prospective data from the Bruneck study. Diabetes Care 26: 1251-1257

22. Hunt KJ, Resendez RG, Williams K, Haffner SM, Stern MP (2004) National Cholesterol Education Program versus World Health Organization metabolic syndrome in relation to all-cause and cardiovascular mortality in the San Antonio Heart Study. Circulation 110:1251-1257

23. Isomaa $B$, Almgren $P$, Tuomi $T$ et al (2001) Cardiovascular morbidity and mortality associated with the metabolic syndrome. Diabetes Care 24:683-689

24. Lakka HM, Laaksonen DE, Lakka TA et al (2002) The metabolic syndrome and total and cardiovascular disease mortality in middle-aged men. JAMA 288:2709-2716

25. Scuteri A, Najjar SS, Morrell CH, Lakatta EG (2005) The metabolic syndrome in older individuals: prevalence and prediction of cardiovascular events: the Cardiovascular Health Study. Diabetes Care 28:882-887
26. Dekker JM, Girman C, Rhodes T et al (2005) Metabolic syndrome and 10-year cardiovascular disease risk in the Hoorn Study. Circulation 112:666-673

27. Juutilainen A, Lehto S, Ronnemaa T, Pyorala K, Laakso M (2006) Proteinuria and metabolic syndrome as predictors of cardiovascular death in non-diabetic and type 2 diabetic men and women. Diabetologia 49:56-65

28. Sundstrom J, Riserus U, Byberg L, Zethelius B, Lithell H, Lind L (2006) Clinical value of the metabolic syndrome for long term prediction of total and cardiovascular mortality: prospective, population based cohort study. Br Med J 332:878-882

29. Kurl S, Laukkanen JA, Niskanen L et al (2006) Metabolic syndrome and the risk of stroke in middle-aged men. Stroke 37:806-811

30. Butler J, Rodondi N, Zhu Y et al (2006) Metabolic syndrome and the risk of cardiovascular disease in older adults. J Am Coll Cardiol 47:1595-1602

31. Jeppesen J, Hansen TW, Rasmussen S, Ibsen H, Torp-Pedersen C (2006) Metabolic syndrome, low-density lipoprotein cholesterol, and risk of cardiovascular disease: a population-based study. Atherosclerosis [Epub ahead of print]

32. Katzmarzyk PT, Church TS, Blair SN (2004) Cardiorespiratory fitness attenuates the effects of the metabolic syndrome on allcause and cardiovascular disease mortality in men. Arch Intern Med 164:1092-1097

33. McNeill AM, Rosamond WD, Girman CJ et al (2005) The metabolic syndrome and 11-year risk of incident cardiovascular disease in the atherosclerosis risk in communities study. Diabetes Care 28:385-390

34. Onat A, Ceyhan K, Basar O, Erer B, Toprak S, Sansoy V (2002) Metabolic syndrome: major impact on coronary risk in a population with low cholesterol levels - a prospective and crosssectional evaluation. Atherosclerosis 165:285-292

35. Resnick HE, Jones K, Ruotolo G et al (2003) Insulin resistance, the metabolic syndrome, and risk of incident cardiovascular disease in nondiabetic American Indians: the Strong Heart Study. Diabetes Care 26:861-867

36. Rutter MK, Meigs JB, Sullivan LM, D'Agostino RB Sr, Wilson PW (2004) C-reactive protein, the metabolic syndrome, and prediction of cardiovascular events in the Framingham Offspring Study. Circulation 110:380-385

37. Takeuchi H, Saitoh S, Takagi S et al (2005) Metabolic syndrome and cardiac disease in Japanese men: applicability of the concept of metabolic syndrome defined by the National Cholesterol Education Program-Adult Treatment Panel III to Japanese men the Tanno and Sobetsu Study. Hypertens Res 28:203-208

38. Ford ES (2004) The metabolic syndrome and mortality from cardiovascular disease and all-causes: findings from the National Health and Nutrition Examination Survey II Mortality Study. Atherosclerosis 173:309-314

39. Liao Y, Kwon S, Shaughnessy S et al (2004) Critical evaluation of Adult Treatment Panel III criteria in identifying insulin resistance with dyslipidemia. Diabetes Care 27:978-983 